\title{
The scientific councils of Alpine protected areas: an overview and analysis of their contribution to linking science and management
}

\author{
Isabelle Arpin, Gaëlle Ronsin, Thomas Scheurer, Astrid Wallner, Fabien Hobléa, Olga Churakova (Sidoro- \\ va), Dominik Cremer-Schulte \& Valerie Braun
}

Keywords: scientific councils, Alps, protected areas

\section{Abstract}

There are numerous protected areas (PAs) within the Alpine Arc. PA practitioners strongly rely on science to gain legitimacy and address complex issues. To this end they establish scientific councils (SCs), a scientific department, or both. Drawing on Alpine and French surveys and an international workshop organized in Chambéry (France) in June 2015, this article gives an overview of SCs in Alpine PAs. It shows that especially France and Switzerland have a high number of SCs and that SCs are highly diverse in their composition, organization, activities and formation. It discusses the capacity of SCs to bring useful (i.e. credible, legitimate and salient) science to PAs and compares them with other ways of linking scientists and PA practitioners. More understanding is needed of how PAs combine different institutional frameworks to engage in boundary science to better grasp the functioning and specific assets and limitations of SCs.

\section{Introduction}

Protected Areas (PAs) in the Alps go back to the establishment of the Swiss National Park in 1914, the first national park in mainland Europe (Kupper 2014; Baur \& Scheurer 2015). To date (ALPARC 2016), 904 PAs over 100 hectares have been established within the perimeter of the Alpine Convention, covering $28 \%$ of the area. These PAs are situated in seven states (Austria, France, Germany, Italy, Lichtenstein, Slovenia, Switzerland) and comprise different types of PA categories: 13 national parks, 13 UNESCO biosphere reserves, 4 UNESCO nature world heritage sites, 11 UNESCO geoparks, 96 regional nature parks, 260 nature reserves (including strict nature reserves) and 507 areas with specific protection (Natura 2000, landscape).

Some of these PAs were created specifically as reference areas for scientific research and monitoring. This is the case of the Swiss National Park (Kupper 2014; Baur \& Scheurer 2015) and of strict nature reserves corresponding to IUCN Category Ia (Dudley 2008: 13). Some labels, such as IUCN Category II (national parks), world heritage sites and geoparks require scientific research for recognition. Without explicitly requiring the implementation of $\mathrm{SCs}$ in biosphere reserves (BRs), UNESCO's Madrid Action Plan (2008) and the Lima Action Plan (2016) strongly promote active and continuing consultations between the scientific and research communities, policy and decision makers, resource managers and resident populations of BRs. In fact, most practitioners resort to science in various degrees whatever the PAs category. Making recommendations for the $21^{\text {st }}$ century American national park system, Colwell et al. $(2014,17)$ tellingly claim that "the need for science [...] has never been greater" and that "the manager and decision maker must rely on science for guidance in understanding novel conditions, threats, and risks to parks now and in the future" $(2014,19)$. There are various reasons for this importance of science to PAs. Science is expected to i) provide important basic information for evidence-based planning, management and communication and therefore to be a means to strengthen the PAs' legitimacy; ii) help address complex issues - e.g. climate change, needs and expectations of inhabitants and visitors (Voll \& Luthe 2014), invasive species, wildlife diseases - through integrative approaches; iii) support the long-term conception of research and monitoring, which are essential for understanding change and developing practices of adaptive management.

Bringing science to PAs and organizing the relationships between PAs practitioners and the scientific community are therefore major issues that PAs managers can address in several ways. Establishing a scientific council (SC) is one of these. Such scientific councils - also termed scientific boards, scientific committees, or research councils - are generally interdisciplinary and multi-institutional entities created on a legal or voluntary basis. Despite their growing significance in some countries, in-depth studies of SCs remain scant. Several cases have been discussed (Selmi 2006; Boudouresque et al. 2013; Delclaux 2013; Sette 2014), but there is no overview or general assessment of their contribution to bringing together scientists and PAs practitioners and to fostering boundary science, i. e. science "that both advances scientific understanding and contributes to decision making" (Cook et al. 2013, 670). This paper, then, has a two-fold objective. First, it aims to offer an overview of SCs in Alpine PAs, and to analyse their role in promoting science in PAs and in linking science and management. Second, it considers the contribution of SCs to establishing links between scientists and PAs practitioners with respect to other institutional frameworks described in the literature about boundary science. It therefore seeks to analyse the potential specific capacity of SCs to act as an interface between scientists and PA practitioners. 


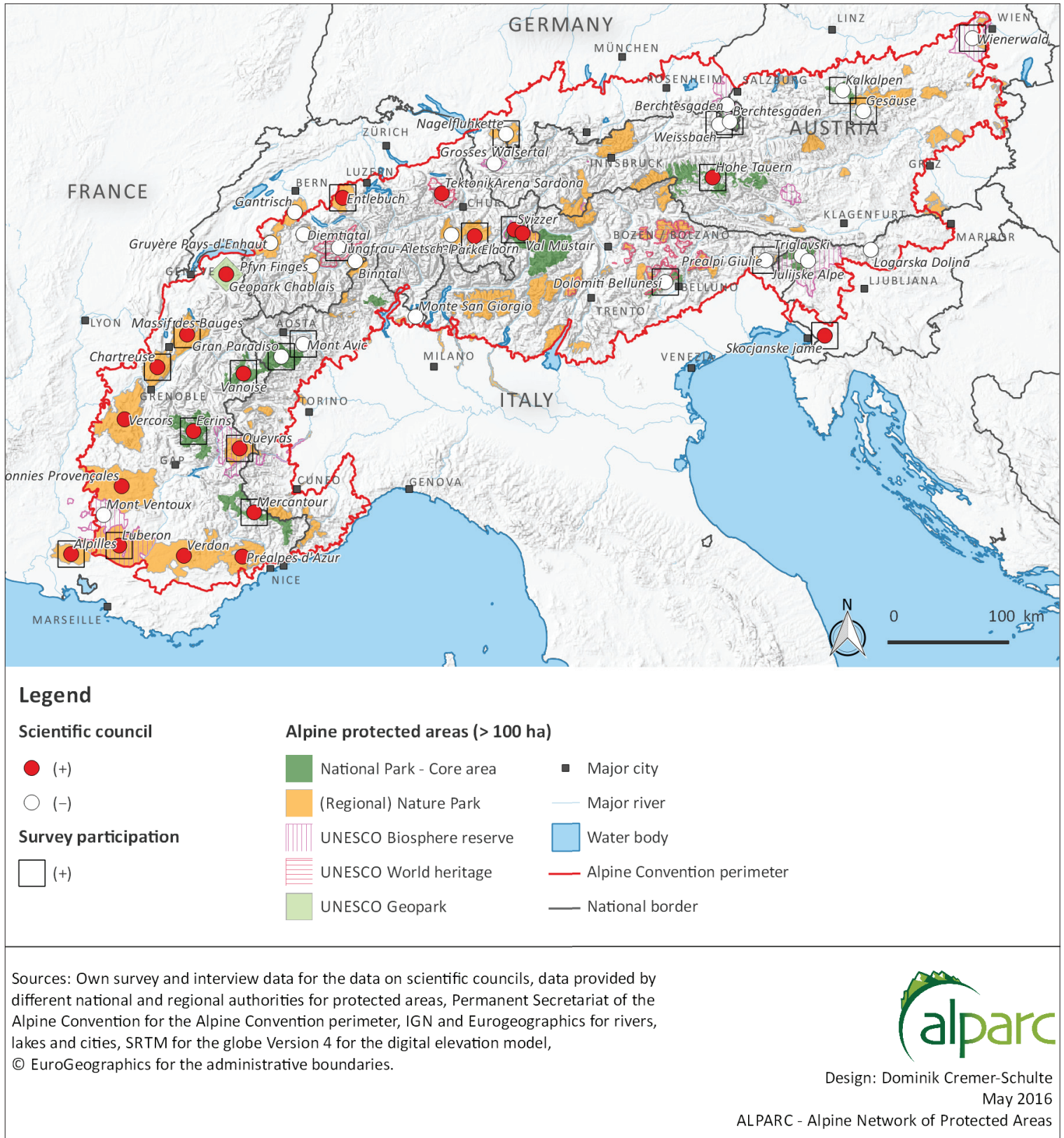

Figure 1 - Map of the Alpine Space indicating Alpine protected areas with or without scientific councils.

\section{Data and method}

This article is based on an Alpine survey and a national survey in France on SCs in PAs. Further information was compiled from the ALPARC database on Alpine PAs and from the discussions in an international two-day workshop on SCs in Alpine PAs held in Chambéry (France) in June 2015, which gathered together some 30 scientists and managers involved or interested in SCs from all Alpine countries (http://www.iscar-alpineresearch.org/workshops/ workshop2015/).

\section{Alpine survey}

A questionnaire was sent twice by the ALPARC office to all Alpine protected areas with a defined contact address $(\mathrm{n}=209)$. This questionnaire posed 20 questions on the main research topics of interest to the PA, the existence of a SC and, if so, its date of creation, composition (number of members, disciplines represented, percentage of academics), its main missions, and the existence of a scientific department and of a scientific journal. As these two calls returned only 13 answers, a selected sample of 30 non-responding PAs from different countries and PA categories was contacted again. Eventually we obtained answers from 29 of them. We included in the analysis all answers from national and regional parks, UNESCO biosphere reserves, world heritage sites and geoparks, that is 25 answers, including 14 answers from PAs with a SC, out of a total 137 PAs in these categories (ALPARC 2016) (see Table 1). Information from presentations and discussions during the Chambéry workshop complements the results of this survey. 
In Switzerland two areas not yet officially acknowledged as national parks were included in the survey but are not shown on the map.

\section{French survey}

A national questionnaire was sent out to all public environmental institutions dealing with nature conservation and land management $(\mathrm{n}=333)$, including 227 PAs across the country (national parks, nature reserves, regional natural parks, world heritage sites, biosphere reserves, geoparks) (Quayle 2015). Wherever possible the questionnaire was sent to the SC chair or else to the PA director. It included more questions than the Alpine questionnaire (e.g. about the members' age group, the amount of official advice delivered per year, the estimated level of activity of the SC), and yielded a refined view of SCs in French Alpine PAs. We found that in France 17 PAs and 20 national nature reserves located within the perimeter of the Alpine Convention have a SC. Many SCs relate to several PAs; for instance, the SC of Vanoise National Park deals with several neighbouring national nature reserves.

\section{Scientific councils in Alpine protected ar- eas: an overview}

To gain an overview of SCs, we sought to document and analyse their distribution across the Alps, their composition and organization, their position between science and management, and their collaboration with one another.

\section{National disparity}

The results indicate that SCs are highly unevenly distributed across Alpine PAs (Figure 1; Table 1). They are almost systematic in France, where they are mandatory in certain PAs (e. g. national parks) and strongly recommended by national federations in others (e.g. natural regional parks), and widespread in Switzerland, where most of them have been created within the last 10 years. In the other countries SCs exist only for singular PAs (e.g. Hohe Tauern National Park in Austria, Škocjanske Jame Regional Park in Slovenia). But the Austrian Man and the Biosphere (MAB) Committee, which had up to now acted as a kind of SC for all Austrian biosphere reserves, has recently set the implementation of a scientific advisory board as a mandatory criterion for these areas.

\section{A broad diversity in composition}

SCs have a broad diversity in size, composition, organization, activity and formation. They have 5 to 40 members, with an average of 16 in the Alpine sample. Members collaborate in SCs on a voluntary basis. They are mainly professional scientists from research institutions and universities (64\% in our Alpine sample), but also science-oriented staff from nature management institutions, local experts and high-level amateurs (36\% in our Alpine sample). Social sciences
Table 1 - Number of surveyed PAs (bold) in relation to the number of Alpine national and regional parks, and UNESCO biosphere reserves, world heritage sites and geoparks with (+) and without (-) scientific council in the European Alps (perimeter of the Alpine Convention). Nature reserves were not included as they usually share a SC with larger PAs. Data: ALPARC database, accessed January 2016; Wallner 2015; data from survey.

\begin{tabular}{|l|l|l|r|r|r|r|r|}
\cline { 2 - 8 } \multicolumn{1}{c|}{} & FR & CH & AT & IT & SI & DE & $\begin{array}{l}\text { Alpine } \\
\text { Arc }\end{array}$ \\
\hline $\begin{array}{l}\text { (+) } \\
\text { SCs }\end{array}$ & $9 / 17$ & $3 / 7$ & $\begin{array}{r}1 / \\
\text { unkn. }\end{array}$ & $\begin{array}{r}0 / \\
\text { unkn. }\end{array}$ & $1 / 1$ & $0 / 0$ & $\begin{array}{r}14 / \\
\text { unkn. }\end{array}$ \\
\hline $\begin{array}{l}\text { (-) } \\
\text { SCs }\end{array}$ & $0 / 2$ & $1 / 8$ & $\begin{array}{r}4 / \\
\text { unkn. }\end{array}$ & $\begin{array}{r}3 / \\
\text { unkn. }\end{array}$ & $0 / 5$ & $3 / 3$ & $\begin{array}{r}11 / \\
\text { unkn. }\end{array}$ \\
\hline Total & $9 / 19$ & $4 / 15$ & $5 / 41$ & $3 / 53$ & $1 / 6$ & $3 / 3$ & $25 / 137$ \\
\hline
\end{tabular}

are represented in all surveyed SCs, a fact linked to cultural heritage conservation now being considered an important mission of PAs and to the recognition that natural and cultural dimensions need to be understood simultaneously. Most SCs meet two to three times a year, but in some cases only once or every second year. Their level of activity, as estimated by the respondents in the French survey, also varies greatly from one PA to the next.

Scientific departments and scientific councils

Some PAs, especially if well staffed, have a scientific department or at least one scientific member of staff in charge of inventorying, monitoring and research activities, and of promoting collaboration with the scientific community. We found no straightforward link between the existence of a SC and the existence of a scientific department (SD) in the PAs and encountered all the possible combinations (Table 2). The most common in our sample are PAs with both a SC and a SD (8 out of 25 , or $32 \%$ ), the least common being PAs without any of these (4 out of 25 , or $16 \%$ ). However, these figures probably do not reflect reality, as PAs with a SC or SD were more prone to respond to the questionnaire than the others. The proportion of PAs without a SC or a SD is certainly higher than $16 \%$.

Table 2 - Distribution of PAs with (+) and without (-) a $S C$ and/or a scientific department (SD) in the Alpine sample.

\begin{tabular}{|l|r|r|r|}
\cline { 2 - 4 } \multicolumn{1}{c|}{} & (+) SC & \multicolumn{1}{c|}{$(-)$ SC } & \multicolumn{1}{c|}{ Total } \\
\hline (+) SD & $8(32 \%)$ & $7(28 \%)$ & $15(60 \%)$ \\
\hline (-) SD & $6(24 \%)$ & $4(16 \%)$ & $10(40 \%)$ \\
\hline Total & $14(56 \%)$ & $11(44 \%)$ & $25(100 \%)$ \\
\hline
\end{tabular}

\section{A science-management gradient}

We found that SCs are situated all along a sciencemanagement gradient rather than at clear-cut positions between science and management. At the science end of this gradient, SCs show a strong implication in proposing and evaluating scientific activities and in insert- 
ing the PAs in scientific networks. These science-oriented SCs are particularly represented in Switzerland, which can be related to the historically strong orientation of Swiss PAs towards science (Kupper 2014; Baur $\&$ Scheurer 2015), and in Austria. These councils tend to be rather small (4 to 15 members in our sample) and rely on scientists with an academic profile and/or precise knowledge of the conservation issues at stake in the PA. In our sample, academics make up $87 \%$ of the councillors in the Swiss SCs, compared to $59 \%$ in the French ones.

At the other end of the gradient, SCs spend a major part of their time and energy dealing with concrete management issues and providing official advice. These more management-oriented SCs are much represented in France where delivering official advice about management plans and authorizations is a mandatory mission of many SCs that has gained increasing significance over the years. There has been a clear tendency in French PAs to shift from the science end to the management end of the gradient, as the volume and technical dimension of the advice have risen while human and financial means dedicated to PAs and their SCs were seriously dwindling.

\section{Collaboration}

Our results suggest that collaboration between SCs remains limited, even when they are spatially close to one another and/or belong to the same category of PA. Moreover, the existence of a SC in a PA is not necessarily associated with increased scientific collaboration with other PAs. Yet there are disparities between SCs here as well, the science-oriented ones tending to be more open to collaboration with other PAs than the more management-oriented ones.

\section{Potential interfaces for linking science and management}

Despite their diversity, SCs also share features that allow grouping them together. In the following section, we offer a tentative definition of SCs and characterize their roles at the boundary between science and management.

\section{Definition}

All SCs are premised on the idea that involving a group of scientists from a variety of disciplines in the PA issues will lead to more comprehensive and accurate knowledge and understanding of these issues and to more evidence-based management decisions. SCs, then, are inter- as well as transdisciplinary and interinstitutional bodies providing a PA with a large range of competences and viewpoints. Another common feature of SCs is that PA staff always participates in the SCs meetings and activities (100\% in our samples). PA staff is normally not entitled to vote when votes are organized (e. g. to elect the chair of the SC, or on a particularly disputed issue) but they provide coun- cillors with information about the issues at stake and participate in the discussions and debates. SCs can be defined as inter- as well as transdisciplinary and multiinstitutional bodies aiming to act as an effective interface between research scientists and PAs practitioners.

Roles

Surveyed PAs mentioned four main roles for SCs: 1) propose a scientific strategy; 2) provide PA practitioners with official advice to PA management, mainly in territorial development and research matters; 3) foster prospective studies to detect environmental change and design adaptive management; 4) contribute to knowledge production and dissemination to cover PA's needs on management, education and communication aspects.

The SC missions are sometimes outlined in research strategies or concepts (Braun 2010) or in mission statements by PA authorities and appear relatively varied. Our surveys confirm that the input of SCs can take a variety of forms, such as developing scientific programmes and strategies, evaluating inventorying and monitoring proposals, alerting the PA practitioners about pressing issues, facilitating the uptake of new scientific concepts and tools, delivering official advice concerning management plans and authorizations, facilitating the PA insertion into scientific networks (e.g. Long-Term Socio-Ecological Research network), organizing scientific events and disseminating scientific information. All these roles can be characterized by their function in linking science and management and grouped into two main types: first, facilitating valuable and tailored knowledge production in PAs and, second, providing advice and guidance related to management operations (evidence-based management).

\section{Facilitating tailored knowledge production in PAs}

\section{Negotiating useful knowledge}

As inter- and trans-disciplinary groups, SCs can facilitate the establishment of links between the PAs and the scientific community and initiate or promote the coproduction of science-based and operational knowledge. For instance, research projects commonly supported by SCs and PA management can be regarded as scientifically valid and as appropriate to the PA's notions of what knowledge is needed and useful in the area.

\section{Navigating research needs}

We found that SCs of Alpine PAs were not systematically active in promoting research on management issues. The SC members can spark new research by informing their peers about the need for science in PAs and the potential of choosing PAs as research sites. They can thus expand the scientific network of PAs in different ways, especially in fields where the practitioners have little knowledge and expertise. Yet we found no example of PA practitioners addressing a complete 
list of research needs to a SC. We assume that this is due to the fact that PA practitioners tend to initiate management-oriented studies outside the SCs.

\section{Disseminating results}

The publication and dissemination of scientific results obtained in PAs in both academic and nonacademic journals are crucial to bringing science to management. Only few PAs (4 out of 25 in our Alpine sample) have their own academic journal and these do not necessarily have a SC. Yet where this is the case, the SC is involved in managing or even editing the journal, as in the Swiss National Park. Quite frequently SCs members are also engaged in more popular forms of dissemination, e.g. newspaper articles, conferences about scientific findings in PAs or participation in events organized by the PAs.

\section{Encouraging adaptive management}

Adaptive management is increasingly recommended where PAs are faced with continuous change, such as a warming climate or urban sprawl. Competences from both science and management are needed to develop adaptive management strategies. SCs sometimes provide some support for such strategies, mainly by recommending concise monitoring programmes, which interact with the evaluation of management measures and encourage the practitioners to monitor the short- and long-term consequences of their management operations.

\section{Providing advice for the management}

\section{Mobilizing science in the making of official advice}

Giving official and robust advice based on up-todate scientific knowledge is one important expected role of SCs that aims to reinforce the credibility and legitimacy of management decisions and actions. Another important role is providing advice from different points of view, leading to more integrated management actions. Asking the SCs for this advice is mandatory for the PAs in some cases and voluntary in others. SCs can also provide the PAs with advice on their own initiative. For instance, in 2010, having learned about a water abstraction project on the Lyonne river, the SC of Vercors Regional Natural Park (France) decided to give official advice about the instream flow of the river.

\section{SCs as early warners}

SCs gather broad know-how from scientific studies on emerging issues, such as the reintroduction of a species, invasive species, or new leisure or sports practices. Some of these issues, e. g. climate change or emerging leisure activities, are due to external developments and therefore sometimes neglected by PA practitioners (Scheurer 2016). Some of the surveyed SCs advise the PAs about their general orientations and policy and are involved in developing or revising their planning or charts where these exist. Regarding scientific progress, SCs sometimes play a role in exploring, in a collective and interdisciplinary manner, the meaning and potential effects for the PAs of trendy approaches (e. g. ecosystem services), expressions (e.g. nature-based solutions), and ways of doing science (e.g. citizen science). The SC members are more likely than the practitioners to be aware of emerging scientific debates and practices. In addition, SCs offer a good arena to reflect on the consequences and stakes of emerging notions, tools (e.g. drones) and approaches in the specific case of PAs rather than in general. The role of SCs, then, is not only to promote research in PAs but to help PAs decide which type of research and, more broadly, which type of knowledge production they should favour.

\section{Discussion}

There are many examples of research operations in PAs that do not lead to management decisions and, vice versa, of management operations that are not science-based. This frequent separation of science and management is not necessarily problematic. Science can be interesting for PAs even when it does not have operational implications and management decisions can derive from political, ethical or economic rather than scientific aspects. Yet, as already suggested, there is a rising demand for linking science and management and for promoting evidence-based management in PAs, following the model of evidence-based medicine (Pullin \& Knight 2001). However, there is now clear and abundant evidence that links between science and operational management are complex, and constructed and maintained over time, rather than linear and automatic (e. g. Hulme 2014).

This also holds for the links between scientists and PA practitioners, who have different goals, practices and concerns, even though they share an interest in the PAs (for an example in Mercantour National Park, France, Granjou et al. 2014). Scientists seek primarily to produce publishable knowledge, whereas the PA practitioners' priority is to achieve sustainable management of these areas, consistent with their status. In other words, knowledge production is an end for the former and a means for the latter, which might give rise to misunderstandings and tensions. Moreover, they may want to know different things, e. g. control factors for managers and response variables for scientists (Sheil, 2001, 1181). Consequently, a key question is how science and management can be linked in PAs. Below we would like to discuss the capacity of SCs to bring useful science to the PAs and compare it with that of other means of linking science and management identified in literature.

Useful science has been defined by Cash et al. (2003) as credible (authoritative, believable, and trusted), legitimate (integrating the values and perspectives of all 
actors) and salient (relevant to decision making and timely). Evaluating to what extent SCs bring useful science to PAs presents major difficulties. Indeed, the influence of their participation in SCs on the scientists and practitioners and the knowledge they produce and use is often indirect, discrete, and delayed rather than direct, obvious and immediate. For instance, it can take months, years or even decades, before repeated exchanges between scientists from various disciplinary backgrounds and practitioners might actually change the participants' views and knowledge practices. Any evaluation must thus remain cautious and open to further investigations. Keeping this in mind, what can we say about the capacity of SCs to increase the usefulness of knowledge mobilized by PA practitioners?

SCs enable their participants to engage in enduring dialogues and conversations over a very broad range of issues and so, to become familiar with other ways of knowing and reasoning, practices and values and to weave tight personal relationships. This long-term dimension has been identified as an important point in boundary science (e.g. see Caudron et al. 2012). Getting familiar with scientists and acquiring good knowledge of their motivations and interests can help PA practitioners decide whether scientific insights will help them tackle a given management problem and, if so, whom they could mobilize. Therefore SCs can arguably lead to more salient knowledge.

Moreover, the high level of trans- and inter-disciplinarity of SCs favours a collective examination and more thorough understanding of complex issues. This may add to the practitioners' difficulty to make decisions but increases the legitimacy of knowledge. However, this increase in legitimacy remains limited as many actors stay outside the knowledge production process.

The contribution of SCs to making knowledge more credible is also contrasted. There are definitely cases where SCs have made substantial inputs, for instance, by evaluating and ameliorating inventorying and monitoring protocols, helping practitioners design their databases and interpret their data, or suggesting research programmes and activities. But there are also many cases where the functioning of SCs does not allow an in-depth scientific examination of the questions raised by managing PAs. This is notably due to the fact that councillors have little time to dedicate to SCs and to the great number and diversity of issues that SCs must examine, generally in short spans of time.

This somewhat ambivalent appreciation of the SC's capacity to bring useful science to PAs invites a comparison with other means of linking science and management to identify their specific assets and limitations. Cook et al. (2013) have distinguished four types of institutional frameworks that facilitate the formation of links between research scientists and resource management agencies: creating boundary organizations (defined below), embedding research scientists in these agencies, establishing formal links between research-focused institutions and these agencies, and encouraging conservation professionals to follow training programmes.

The SCs we found in Alpine PAs do not fit exactly in any of these frameworks. Members of SCs are not embedded in PAs and SCs rarely intervene in the training of PA staff. They sometimes facilitate links between research-focused institutions and PAs, but this is no general rule. Boundary organizations (BOs) (Guston 2001) correspond to the type of institutional framework identified by Cook et al. (2013) which SCs resemble most. BOs are notably characterized by the fact that they include people from different professional worlds (the scientific world and the management world in SCs), produce boundary objects (Star \& Griesemer 1989, 393; e. g. official advice in SCs) and have a dual system of accountability. One important difference between SCs and BOs is the fact that participants in SC activities do not have the same status, as the PA practitioners are usually not official members of SCs.

Other forms of links between scientists and practitioners described in the literature are collaborative research projects associating practitioners and scientists (Caudron et al. 2012), and embedded experiences, "which can range from conducting bighly structured research to being a casual participant-observer in another community" (Jenkins et al. 2012, 740). The SCs found in Alpine PAs present two major features considered crucial in these forms of links: their high level of trans- and inter-disciplinarity (see Young et al. 2014), and their long-term dimension. But, unlike collaborative research programmes and embedded experiences, they function in an intermittent manner and do not directly enable scientists and practitioners to engage in intensive collaborative work. Save for a few exceptions, they cannot lead to the type of collaboration and outcome described by Caudron et al. (2012), where river managers and scientists embarked together on a collaborative research action. Meeting PA practitioners (for a scientist) or scientists (for a PA practitioner) three times a year, even over 10 or 20 years, does not amount to working together intensively in a three-year research project or during a one-month stay in their institution.

\section{Conclusion}

Due to their simultaneously intermittent and longterm functioning, and high level of inter- and transdisciplinarity, SCs of PAs appear as original tools to bring together scientists and PAs practitioners. They have specific assets and limitations and cannot be confused with the tools examined so far in the literature about boundary science.

Their characteristics enable SCs to effectively foster the creation of a sense of familiarity between the scientists and the PA practitioners involved in the SCs activities. While participating in the SCs of PAs, scien- 
tists and practitioners learn to take into account different ways of knowing and reasoning and can mobilize the personal relationships developed in SCs in other contexts. But SCs are not meant and do not usually have the means to directly generate intensive collaborative work or embedded experiences for scientists or for practitioners. Even if their composition, functioning and coordination can certainly be improved (Arpin et al. 2016), they appear to complement other ways of linking scientists and PAs managers. PAs, then, should not rely solely on SCs to diversify and tighten their links with the scientific community. To better grasp the functioning and specific assets and limitations of SCs, more understanding is needed of how PAs can combine different institutional frameworks to engage in boundary science.

\section{Acknowledgements}

We thank two anonymous reviewers for very helpful comments on a previous version of this article.

This work has been supported by LABEX ITEM ANR-10-LABX-50-01. We thank all participants in the workshop held in Chamberry in June 2015 for their input to the discussions, these are Bernard Bal, Carole Birck, Massimo Bocca, Philippe Bourdeau, JeanJacques Brun, Arnaud Cosson, Jean-Marcel Dorioz, Matej Gabrovec, Heidi Humer-Gruber, Daniel Kreiner, Gilles Landrieu, Jean-François Lopez, Grégory Loucougaray, Emmanuel Michau, Robert Moutard, Michele Ottino, Guido Plassmann, Neil Quayle, Henri Rougier, Dominik Siegrist, Edouard Simonian, Sophie Tocreau, Michael Vogel, Chris Walzer. We also thank Labex ITEM and ISCAR for financing this Workshop, as well as Vanoise National Park, the University of Savoie and ALPARC for organizational support.

\section{References}

ALPARC 2016. Rapport annuel 2015. Réseau alpin des espaces protégés, Chambéry.

Arpin, I., A. Wallner, T. Scheurer \& V. Braun 2016. Recommendations for establishing or renewing scientific councils in protected areas. eco.mont 8 (1): 56-59.

Baur, B. \& T. Scheurer 2015. Au cour de la nature. Cent ans de recherches au Parc national suisse. NationalparkForschung in der Schweiz 100/II.

Boudouresque, C.-F., G. Sellier, C. Maurer \& A. Barcelo 2013. Un demi-siècle de recherche scientifique dans le cadre du Parc national de Port-Cros. Scientific Reports of Port-Cros national Park 27: 23-27.

Braun, V. 2010. Research concepts in protected areas in the Alps. eco.mont 2(2): 55-60.

Cash, D.W., W.C. Clark, F. Alcock, N.M. Dickson, N. Eckley, David H. Guston, J. Jager \& R.B. Mitchell 2003. Knowledge systems for sustainable development. Proceedings of the National Academy of Sciences of the USA 100: 8086-8091.
Caudron, A., L Vigier \& A. Champigneulle 2012. Developing collaborative research to improve effectiveness in biodiversity conservation practice. Journal of Applied Ecology 49: 753-757.

Colwell, R., S. Avery, J. Berger, G.E. Davis, H. Hamilton, T. Lovejoy, S. Malcom, A. McMullen, M.J. Novacek, R.J. Roberts, R. Tapia \& G. Machlis 2014. Revisiting Leopold: Resource stewardship in the national parks. Parks 20.2.

Cook, C.N., M.B. Mascia, M.W. Schwartz, H.P. Possingham \& R.A. Fuller 2013. Achieving Conservation Science that Bridges the Knowledge-Action Boundary. Conservation Biology 27: 669-678.

Delclaux, J. 2013. Les conseils scientifiques et la gouvernance des parcs nationaux français. L'exemple du parc national de Port Cros. Mémoire de fin d'études.

Dudley, N. 2008. Guidelines for Applying Protected Area Management Categories. IUCN, Gland, Switzerland.

Granjou, C., I. Mauz, M. Barbier \& P. Breucker 2014. Making taxonomy environmentally relevant. Insights from an All Taxa Biodiversity Inventory. Environmental Science \& Policy http://dx.doi.org/10.1016/j. envsci.2014.01.004:254-262.

Guston, D.H. 2001. Boundary organizations in environmental policy and science: an introduction. Science, Technology and Human Values 26: 399-408.

Hulme, P.E. 2014. Bridging the knowing-doing gap: know-who, know-what, know-why, know-how and know-when. Journal of Applied Ecology 51: 1131-1136.

Jenkins, L.D, S.M. Maxwell \& E. Fisher 2012. Increasing conservation impact and policy relevance of research through embedded experiences. Conservation biology 26: 740-742.

Kupper, P. 2014. Creating wilderness. A Transnational History of the Swiss National Park. New York- Oxford.

Pullin, A.S. \& T.M. Knight 2001. Effectiveness in conservation practice: pointers from medicine and public health. Conservation Biology 15: 50-54.

Quayle, N. 2015. Panorama national des conseils scientifiques de l'action publique environnementale. Mémoire de master 1 «Techniques, sciences et décisions », institut d'études politiques de Grenoble.

Scheurer, T. 2016. The role of science in governing and managing the parks of the future. In: Hammer, T., I. Mose, D. Siegrist \& N. Weixelbaumer (eds.), Parks of the Future. Protected Areas in Europe Challenging Regional and Global Change: 241-246. Oekom, Munich.

Selmi, A. 2006. Administrer la nature. Paris: Editions de la MSH, Editions Quae.

Sette, A. 2014. Le conseil scientifique du parc national de la Vanoise : une organisation-frontière entre science et gestion conservatoire de la biodiversité. Mémoire de master. Institut d'études politiques de Grenoble.

Sheil, D. 2001. Conservation and biodiversity monitoring in the Tropics: Realities, priorities, and distractions. Conservation Biology 15: 1179-1182.

Star, S.L. \& J.R. Griesemer 1989. Institutional ecology, 'translations' and boundary objects: Amateurs 
and professionals in Berkeley's Museum of vertebrate zoology. Social Studies of Science 19: 387-420.

UNESCO 2008. Madrid Action Plan for Biosphere Reserves (2008-2013). Available at: http://unesdoc. unesco.org/images/0016/001633/163301e.pdf (accessed 27/04/2016)

UNESCO 2016. Lima Action Plan for UNESCO's Man and the Biosphere (MAB) Programme and its World Network of Biosphere Reserves (2016-2025). Available at: http://www.unesco.org/new/fileadmin/ MULTIMEDIA/HQ/SC/pdf/Lima_Action_Plan_ en_final.pdf (accessed 27/04/2016)

Voll, F. \& T. Luthe 2014. A systemic perspective on sustainable governance of protected areas. eco.mont 6(1): 15-22.

Wallner, A. 2015. Organisation of Park research in Switzerland: Bringing together common and specific issues. International Workshop "Interface between science and mountain protected areas: The role of scientific councils". Chambéry (F), 25-26 June 2015.

Young, J., K.A. Waylen, S. Sarkki, S. Albon, I. Bainbridge, E. Balian, J. Davidson, D. Edwards, R. Fairley, C. Margerison, D. McCracken, R. Owen, C.P. Quine, C. Stewart-Roper, D. Thompson, R. Tinch, S. Van den Hove \& A. Watt 2014. Improving the science policy dialogue to meet the challenges of biodiversity conservation: having conversations rather than talking at one another. Biodiversity and Conservation 23: 387-404.

\section{Authors}

\section{Isabelle Arpin}

is a sociologist at the Grenoble Centre of Irstea (national research institute of science and technology for environment and agriculture). She studies contemporary ways of investigating and managing nature and is particularly interested in the interface between scientists and nature managers. Université Grenoble Alpes, Irstea, UR DTGR, 2 rue de la Papeterie-BP 76, F 38402 St-Martin-d'Hères.

\section{Gaëlle Ronsin}

is a $\mathrm{PhD}$ student of sociology studying scientific councils of protected areas in the French Alps on different scales from a social, organizational and professional perspective. Université Grenoble Alpes, Irstea, UR DTGR, 2 rue de la Papeterie-BP 76, F 38402 StMartin-d'Hères. Laboratoire EDYTEM, Université de Savoie/CNRS, Campus Scientifique F 73376 Le Bourget-du-Lac cedex. Labex ITEM

\section{Thomas Scheurer}

is executive manager of the Research Council of the Swiss National Park and the International Scien- tific Committee for Alpine Reserach (ISCAR) at the Swiss Academies of Arts and Sciences. Swiss National Park Research Council, Swiss Academy of Arts and Sciences, Laupenstrasse 7, CH 3001 Bern.

\section{Astrid Wallner}

is the coordinator for research on Swiss parks. She studied social anthropology and geography at the University of Zurich (Switzerland) and worked on the local acceptance of protected areas in Switzerland and the Ukraine. Swiss Park Research Coordination Office, Swiss Academy of Arts and Sciences, Laupenstrasse 7, CH 3001 Bern.

\section{Fabien Hobléa}

is a lecturer at the department of Geography of the University Savoie Mont Blanc. He is a member of several scientific councils of protected mountain areas and participates in the working group on scientific councils of Alpine protected areas within LabEx Item (Innovation in Mountain Territories). Laboratoire EDYTEM, Université de Savoie/CNRS, Campus Scientifique F 73376 Le Bourget-du-Lac cedex.

\section{Olga Churakova (Sidorova)}

is a researcher in the Forest Ecology group at ETH Zürich, carrying out a research project at the Swiss National Park within the Marie-Heim Vögtlin SNSF programme, and also works as a scientist at the Institute of Geological Sciences, Dendrolab.ch, University of Bern, Switzerland. ETH Zurich, Institute of Environmental Sciences, Forest Ecology Group, 8092 Zurich (Switzerland); University of Bern, Institute of Geological Sciences, Dendrolab.ch, CH 3012 Bern.

\section{Dominik Cremer-Schulte}

is regional development project coordinator at ALPARC - the Alpine network of protected areas. He is also responsible for GIS and the ALPARC spatial data base. He holds an engineering degree in spatial planning (TU Dortmund) and is a $\mathrm{PhD}$ candidate in (spatial) economics (Irstea Grenoble and Université Grenoble Alpes). ALPARC, 256, rue de la République, F 73000 Chambéry.

\section{Valerie Braun}

works at the Institute for Interdisciplinary Mountain Research and is managing editor of eco.mont. Institute of Interdisciplinary Mountain Research, Austrian Academy of Sciences, Technikerstr. 21 a, A 6020 Innsbruck. 